\title{
Asymmetric sulfoxidation of thioether catalyzed by soybean pod peroxidase :kinetic model
}

\author{
yuanyuan zhang ${ }^{1}$, huiling $\mathrm{Li}^{1}$, zhiyong $\mathrm{Wang}^{1}$, depeng $\mathrm{Li}^{1}$, and xin $\mathrm{Gao}^{1}$
}

${ }^{1}$ Affiliation not available

November 29, 2020

\begin{abstract}
The asymmetric sulfoxidation catalyzed by soybean pod peroxidase (SPP) in water-in-oil microemulsions were carried out with the yield of $91.56 \%$ and e.e of $96.08 \%$ at the activity of SPP of $3200 \mathrm{U}$ ml-1 and 50 for $5 \mathrm{~h}$. The mechanism with a two-electron reduction of SPP-I is accompanied with a single-electron transfer to SPP-I and nonenzymatic reactions, indicating that three concomitant sub-mechanisms contribute to the asymmetric oxidation involving five enzymatic and two nonenzymatic reactions, which can represent the asymmetric sulfoxidation of organic sulfides to form enantiopure sulfoxides. With $5.44 \%$ of the average relative deviation, a kinetic model fitting experimental data was developed. The enzymatic reactions may follow ping-pong mechanism with substrate inhibition of $\mathrm{H} 2 \mathrm{O} 2$ and product inhibition of esomeprazole, while nonenzymatic reactions, a power law. Those results indicate that SPP with a lower cost and higher thermal stability may be used as an effective substitute for Horseradish Peroxidase.
\end{abstract}

\section{Hosted file}

manuscripts AJ.pdf available at https://authorea.com/users/364771/articles/495887-asymmetricsulfoxidation-of-thioether-catalyzed-by-soybean-pod-peroxidase-kinetic-model 